the use of members. The Federal Handbook gives general accounts of the scientifically important aspects of the country, and it was some time ago placed in the hands of prospective visitors. It is the intention of the Commonwealth Government also to present a copy to each member of the general committee and to each foreign corresponding member. An admirable supplement to this work is given by the handbooks issued by the respective States, and by booklets which deal specifically with the localities chosen as objects of excursions.

It is a misfortune that so great a proportion of the time which members can spare from their work in Great Britain must be spent on the ocean; but it may be conceded that the proposed arrangements in Australia, if successfully carried through, will have offered to the visiting party as full and well-chosen an opportunity for achieving the objects of a colonial meeting of the British Association as it is possible to obtain in the short space of three and a half weeks, devoted to visiting four cities distributed along a stretch of railway line $\mathrm{r} 800$ miles in length.

\section{THE ELECTRIC EMISSIVITY AND THE DIRECTIVE DISINTEGRATION OF HOT BODIES.}

[HAT department of physics which concerns 1 itself with the electrical and kindred properties of incandescent bodies has recently attracted a good deal of controversial attention. From the outset, the subject aroused great interest, possibly in view of its speculative possibilities for solar physicists and others, and numerous workers have carried its development into great detail and some complexity. In a short resumé of the two phenomena specifically mentioned in the title of this article, we can do no more than touch on general outlines. Of the several aspects, the electrical one, now generally known as "thermionics," calls for first mention.

Electric Emissivity.-It was Guthrie in 1873 , at the Royal School of Mines, who did pioneer work on what we now know to be a characteristic feature of incandescent bodies, and that is, to put it simply, their property of emitting an excess of positive electricity at a red heat, and at higher temperatures, a much larger excess of negative. The positive electrification, we have reason to believe, is carried chiefly by atoms or molecules of either occluded gas (such as CO), or impurities such as the alkali metals.

The degree of the negative emissivity at high temperatures was shown by subsequent workers, Elster and Geitel among others, to depend not only on the body and its temperature, but also on the nature and pressure of the surrounding gas. Sir J. J. Thomson established the fact that no matter what the nature of the hot body, the electron was the prime agent in the transport of the negative electricity; and later, Prof. O. W. Richardson (then a student at the Cavendish Laboratory), in his early work on a subject now associated with his name, concluded that these thermionic currents were due to a kind of "electric evaporation" of the unattached electrons ir: the solid.

Treating the problem from this point of view, Richardson derived his well-known expression :-

$$
I=a \theta^{2} C^{-l, j},
$$

where $I$ is the saturation current, $\theta$ the absolute temperature, and $a$ and $b$ are constants for any particular material. As will be seen, the formula (which is identical in type with that of Kirchoff for vapour-pressure, and shares its peculiar "elasticity") contemplates the electric emission as due solely to the effect of temperature.

It was not until rgi 2 that doubts were first cast on the adequacy of this explanation. Pring and Parker (Phil. Mag., January, I912), working in Sir Ernest Rutherford's laboratory at Manchester, took especial pains to purify and free from gas a sample of carbon rod, and in consequence of these precautions found that the thermionic emission from the rod in a high vacuum was reduced to a value of the order of a million times smaller than was indicated by Richardson's formula. Later, Pring (Proc. Roy. Soc., November, I9r3) continued and refined these experiments, and succeeded in further reducing the ionisation currents.

Clearly, Richardson's constants for carbon needed amending, as he himself readily recog. nised, though the two investigators still find themselves in disagreement (Richardson, Proc. Roy. Soc., May, 1914) as to the extent of the correction which is afforded by Pring's experiments.

This point remains at issue, but the further observations of Pring on the effect of introducing traces of different gases into the vessel containing the carbon strongly favour his contention that the thermionic currents owe their origin, at any rate in great part, to an interaction, probably of a cyclic character, between the carbon and the surrounding gas. Pring tried a number of gases -helium, argon, nitrogen, carbon dioxide, etc.and found that the ionisation effects at very low pressures followed closely the order of the known chemical activities. It may be noted that Fredenhagen, working about this time on sodium and potassium in a high vacuum, also concluded that the thermionic effect was a chemical one.

In the meantime, Harker and Kaye (Proc. Roy. Soc., February, I9I2), at the National Physical Laboratory, had approached the question from quite another point of view. With the object of accentuating these high-temperature currents, they had recourse to the carbon-tube resistance furnace. Under these conditions they obtained electrical emissions of unparalleled magnitude from carbon at atmospheric pressure, no electromotive force being applied. At temperatures approaching $3000^{\circ} \mathrm{C}$. the thermionic current attained a value of several amperes, and readily lit up a nest of small glow-lamps; it was no longer a question for electrometer or sensitive galvanometer. These investigators concluded that the effect in their experiments was largely conditioned by the furnace-gas and the expulsion of the impurities present in the carbon. In more recent work,

NO. 2335, VOL. 93] 
Kaye and Higgins have extended these furnace experiments to the case of the alkaline earths and a number of metals. When these substances were suddenly introduced into the furnace, even more remarkable electric currents were recorded, amounting at $2500^{\circ} \mathrm{C}$. to about 4 amperes per sq. $\mathrm{cm}$. with barium oxide, about 2 amperes per sq. $\mathrm{cm}$. with boiling tin, and rather less with boiling iron.

Without a doubt, the emission with baryta is one owing its magnitude in great part to chemical action; and this view, it may be noted, tallies with the opinion now generally held that the activity of this substance (and of lime) in the Wehnelt kathode, is effected largely through the intermediary of the residual or occluded gas, or possibly of the platinum kathode.

These conclusions as to the part played by the surrounding gas are on all fours with the results of recent work by Fredenhagen and Küstner (Phys. Zeit., January I5, I9I4), and Hallwachs and Wiedmann (Berl. Ber., January, I914) on the photo-electric effect. These observers took steps to renew continuously (either by scraping or distillation) the surface of a metal $\left(Z_{n}\right.$ and $\mathrm{K}$ respectively) in a vacuum of exceptional excellence, and then found that, if elaborate precautions were taken to remove any occluded gas as fast as it was released, no electronic emission such as is ordinarily produced by ultra-violet light could be detected. The inference is that chemical action plays a prominent part in photo-electricity, just as in many thermionic experiments.

But there are certain cases described by Richardson and his coadjutors, and more recently by Langmuir (Phys. Rev., December, I913), where the temperature factor is apparently competent to explain quantitatively the observed phenomena; and the present position appears to be that several effects may be concerned in the generation of electricity by hot bodies, viz. :-

(I) That due purely to temperature;

(2) That due to chemical reaction; and probably

(3) That due to a change of state-volatilisation and possibly liquefaction.

It does not follow that all the various causes will conspire to help each other. For example, Kaye and Higgins noticed that boiling brass gave out at $2500^{\circ} \mathrm{C}$. a large emission of positive electricity, and it may be that in this case the vaporisation effect was positive and sufficiently great to mask completely the negative emission due to other causes.

The part played by volatilisation has not receired so much attention as the others, but the experiments at the National Physical Laboratory offer support in favour of this view, which, after all, is but an extension of what is well known in cases of bubbling and splashing of liquids at moderate temperatures.

The Directive Volatilisation of Metals.-Evidence of the volatility of metals at temperatures well below their melting points is of long standing. A familiar illustration is furnished by the blackening of tungsten and carbon filament lamps.
Deposits of definite outline can often be detected on the bulbs of the lamps, and the blackening frequently takes the form of a parallel band of deposit which is confined to the glass immediately opposite the windings of the filaments. The fact seems to point to the projection of particles in definite directions from the filament.

We are led to the consideration of a number of researches, which have established the fact that the particles which are given off from the surface of a metal during volatilisation tend to travel in straight lines at right angles to the surface. This rectilinear emission appears to have been first noticed by Dunoyer (Comptes rendus, I $5^{2}, \mathrm{p}$. 592 ) at Paris in rgrx. In his experiments a piece of sodium metal was placed at the bottom of a vessel which was highly exhausted. Above the scdium were mounted two parallel screens, in each of which was a small hole, the one being vertically above the other. The sodium was heated to about $400^{\circ} \mathrm{C}$., so that the liquid metal was vaporising freely, though not actually boiling. Dunoyer found that if a small obstacle was placed above the upper diaphragm a shadow (with umbra and penumbra) was clearly traced out in the deposit of sodium condensed on a screen above the upper diaphragm. Evidently the metal was propagated in straight lines, and Dunoyer looked to the individual molecules as the carriers of the metal, these molecules being able to maintain a straight course owing to the low gas pressure.

But similar experiments carried out by Reboul and de Bollemont (Journ. de Phys., July, I9I2) cannot be quite so simply explained. These experimenters mounted vertically within an electric furnace two small sheets of metal facing each other and a few millimetres apart. One sheet (which was usually of platinum) acted merely as a receiving screen, while the other consisted of the metal the volatilisation of which was being studied. With the furnace below $400^{\circ} \mathrm{C}$., no results were obtained; but at temperatures between $400^{\circ} \mathrm{C}$. and $900^{\circ} \mathrm{C}$. it was found that if the volatilising sheet was of copper or silver, a black deposit, which closely followed the shape of the emitting metal, was obtained on the screen. The extent of the effect increased rapidly with the temperature. In air at atmospheric pressure the best results were secured at about $\mathrm{r} \mathrm{mm}$. distance, $3 \mathrm{~mm}$. being the greatest distance at which definite deposits vere secured.

Fig. I shows the cruciform deposit obtained in air at atmospheric pressure from a copper sheet cut in the form of a small cross. In this example, the furnace temperature was $85^{\circ} \mathrm{C}$., the range $x \mathrm{~mm}$., and the time of exposure 30 secs.

Reboul and de Bollemont repeated the observations under various conditions. In oxygen the effect was enhanced; in a vacuum, the deposit gained in sharpness of outline. Curiously enough, in hydrogen, the edges of the strip seemed to be the only active regions, so that the deposit merely reproduced the outline of the strip.

NO. 2335, VOL. 93] 
Kaye and Ewen (Proc. Roy. Soc., June, I9r3), using an arrangement not very dissimilar to that of Dunoyer, obtained some interesting "shadow" deposits with iron. One of these, illustrated full size in Fig. 2, shows the image obtained by the normal interposition of two square-holed diaphragms between a screen and a strip of iron heated electrically in a vacuum to $1000^{\circ} \mathrm{C}$. for a few hours.

This rectilinear projection is probably closely associated with what is sometimes termed sput-

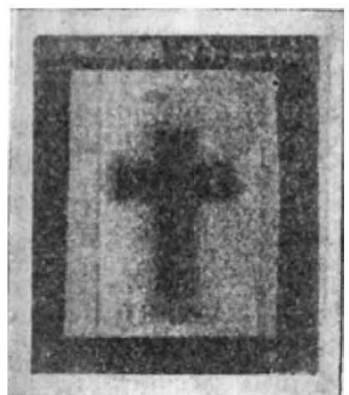

FIG. I.-D pusit cast y heated copper strip, cruciform in shape, on screen $\mathrm{x} \mathrm{mm}$. away. tering, i.e., the expulsion of molecules, not singly, but in relatively large aggregates, from the surface of hot metals. These projected particles would, owing to their greater mass, be less liable to scattering at high pressures by the surrounding gas molecul:s, and so would preserve their direction of flight longer than particles with dimensions not far from molecular.

Fig. 3 is a photomicrograph (taken by $\mathrm{Mr}$. Ewen, Zeit. f. Metallographie) showing the pits which developed in the surface of a specimen of wrought iron when heated for about 4 hours at $1000^{\circ} \mathrm{C}$. in a vacuum.

There are grounds for suspecting that the mechanism of sputtering is partly electrical, for it was found that the passage of the heating current through the specimen itself predisposed the metal to more rapid disintegration than if it

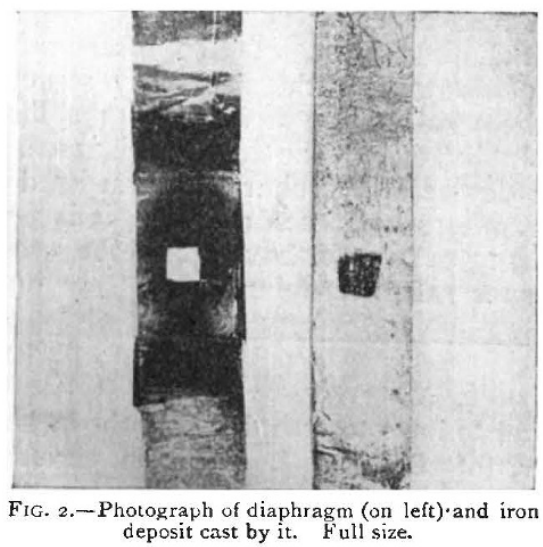

were heated under the same conditions in a furnace.

The practical study of high-temperature furnace experiments on thermionics finds raison d'être, if such were needed, in its applicability to the problems of solar electricity. If it may be regarded as legitimate to extrapolate from the results obtained over the range of temperatures (up to $3000^{\circ}$ C.) possible in the carbon resistance furnace, then it would appear that at the estimated temperature of the sun $\left(5500^{\circ} \mathrm{C}\right.$.) the elec- trical emissions would amount to many millions of amperes. Thus, notwithstanding the gigantic areas of sun-spots, there is no difficulty in accounting for the enormous currents necessary to produce the magnetic fields (from 2000 to 5000 gauss), which Hale has shown to be associated with the whirlpools in sun-spots. On the same lines, we may seek to explain also the sun's general magnetism, the vertical component of which at the poles is estimated by Hale at about 50 gauss.

In conclusion, we may refer briefly to two practical developments of the study of the molar and electric emissions from hot metals. The halfwatt lamp and the new Coolidge X-ray tube are first-fruits culled by observers equipped with a knowledge of the results of pure research, and

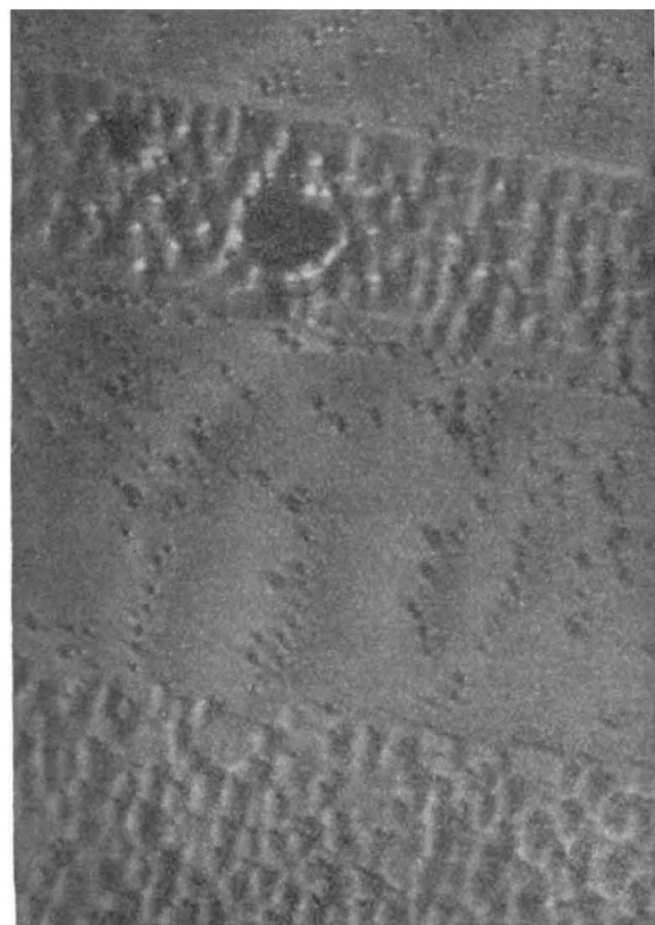

Fig. 3.-Photomicrograph of surface of iron strip which has been heated in vacuo, showing pits produced by volatilisation. $\times 1400$.

an ability to apply them to industrial requirements. The work, carried out at the General Electric Co.'s research laboratory in Schenectady, is worthy of the attention of those among us who, severely practical and immediately utilitarian, seek to deprecate the study of pure science in this country.

G. W. C. Kaye.

\section{A FORGED "ANTICIPATION" OF MODERN SCIENTIFIC IDEAS.}

I $\mathrm{N}$ the I9I3 presidential address to the Linnean Society, noticed in NATURE for January 22, I9I4, Prof. Poulton gave an account of an American booklet by $\mathrm{G}$. W. Sleeper, dated $\mathrm{W} 849$. The work, if genuine, was an extraordinary anticipa- 